Original Article

\title{
ANTIBACTERIAL ACTIVITY OF SYNTHESIZED SILVER NANOPARTICLES BY SIMAROUBAGLAUCA AGAINST PATHOGENIC BACTERIA
}

\section{P. CHANDRAPPA ${ }^{1}$, N. CHANDRASEKAR ${ }^{2}$, M. GOVINDAPPA ${ }^{2}$, CHAITRA SHANBHAG ${ }^{1}$, UTTAM KUMAR SINGH ${ }^{1}$, JAYASHRI MASARGHAL ${ }^{1}$}

1Department of Biotechnology, Shridevi Institute of Engineering and Technology, Sira Road, Tumkur 572106, Karnataka, India, ${ }^{2}$ Department of Chemistry, Shridevi Institute of Engineering and Technology, Sira Road, Tumkur 572106, Karnataka, India, Email: chandrappacp@gmail.com

Received: 27 Jan 2017, Revised and Accepted: 20 Apr 2017

\section{ABSTRACT}

Objective: The present study outline the plant-mediated synthesis of silver nanoparticles (AgNPs) using leaf extract Simaroubaglauca, which act as both reducing and stabilizing agent.

Methods: Formation of silver nanoparticles was confirmed by primarily by Ultraviolet/visible spectroscopy. X-ray diffraction studies revealed the crystallinity of the nanoparticles. The scanning electron microscopy was carried out to determine the mean particle size, as well as the morphology of the NPs and the composition of elements, was studied with Energy Dispersive X-ray analysis (EDS).

Results: The silver nanoparticles were spherical in shape with a mean size of $23 \mathrm{~nm}$. The EDS showed strong optical absorption peak at $3 \mathrm{keV}$ and it was confirmed the formation of AgNPs. The synthesised AgNPs further utilized for the evaluation of antibacterial activity and shown significant antibacterial activity against Escherichia coli, Pseudomonas aeruginosa, Enterobacter and Klebsiella pneumonia at $50 \mu \mathrm{g} / \mathrm{ml} \mathrm{and} 100 \mu \mathrm{g} / \mathrm{ml}$ concentrations.

Conclusion: The synthesised silver nanoparticles have been characterised by UV-vis, SEM-EDAX and XRD to determine the sizes and shapes of the silver nanoparticles.

Keywords: Simaroubaglauca, Silver nanoparticles, Leaf extract, Bioreductant, Antibacterial

(C) 2017 The Authors. Published by Innovare Academic Sciences Pvt Ltd. This is an open access article under the CC BY license (http://creativecommons.org/licenses/by/4.0/) DOI: http://dx.doi.org/10.22159/ijcpr.2017v9i4.20629

\section{INTRODUCTION}

Every person will suffer from either one or other diseases caused by various bacteria at least once in his or her lifetime that shows resistance against one or two existed antibiotics and which leads a severe public health problem $[1,2]$.

Hence, there is top-priority to develop alternative treatments for bacterial diseases. Silver was being used in the field of medicine for antimicrobial applications such as burn therapy [3, 4], removal of microbes on textile fabrics [5-7], and inhibition of colonization of bacteria on catheters [8-10]. As antimicrobial agents, Nano-silver systems offer many advantages. They own a very high effect towards a broad range of microbes and parasites, even at low doses and does not shows toxicity in humans and relatively inexpensive.

Thus Silver has been suspended within a wide variety of materials, under various forms such as salts, immobilized ions or metallic nanoparticles [11-13]. Plasma membrane, many important enzymes and DNA of the bacteria are important targets for silver ions [14-18].

Simaroubagluca is one of the important traditional medicinal plants due to the presence alkaloids, flavonoids, carbohydrates, glycosides, a phenolic compound, tannins, terpenoids, cardenolides, saponins, fixed oils which can usually account for their therapeutic action includingAntibacterial, antiviral, anti-inflammatory, antiprotozoal and antitumor activities [19]. But never synthesized and characterized silver nanoparticles by the extracts of Simaroubaglauca.

Here, we synthesized silver nanoparticles using an aqueous leaf extract obtained from Simaroubaglauca. In addition, to consider the biological application of our work, antibacterial evaluation was carried out.

\section{MATERIALS AND METHODS}

Preparation of leaf extract

Silver nitrate $\left(\mathrm{AgNO}_{3}\right)$ was purchased from sigma-aldrich and fresh Simaroubagluca leaves were collected from Shridevi Institute of Engineering and Technology Campus in Tumakuru of Karnataka, India. The collected leaves were washed thoroughly and cut into small pieces. Finely incised SIMAROUBAGLAUCA leaves (20g) were weighed and transferred to $500 \mathrm{ml}$ conical flask containing $100 \mathrm{ml}$ of distilled water and gently mixed and boiled for $5 \mathrm{~min}$.

The obtained extract was collected filtered through Whatman No.1 filter paper and the filtrate was collected in $250 \mathrm{ml}$ Erlenmeyer flask and stored at $4{ }^{\circ} \mathrm{C}$ for further use.

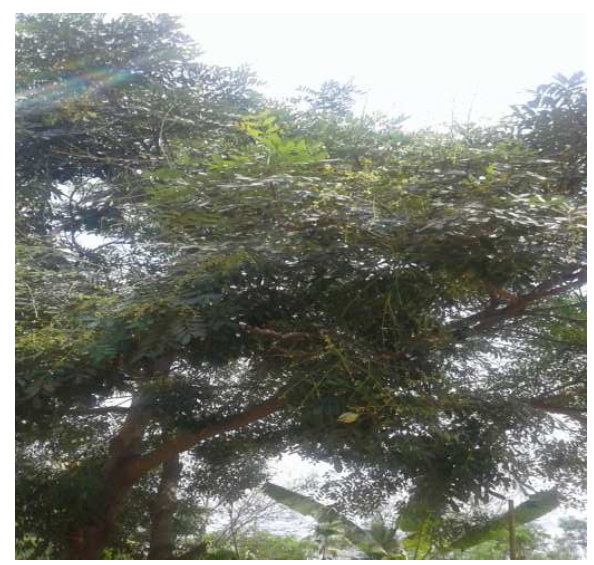

Fig. 1: Simaroubaglauca 


\section{Synthesis of silver nanoparticles using leaf extract}

Silver nanoparticles were synthesized by mixing $5 \mathrm{ml}$ of Simaroubagluca leaf extract with $50 \mathrm{ml}$ of silver nitrate aqueous solution $(1 \mathrm{mmol})$ and stirred for $10 \mathrm{~min}$ at $30^{\circ} \mathrm{C}$. Reduction rapidly occurs as indicated by a pale bluish colour after $30 \mathrm{~min}$ indicating the formation of silver nanoparticles. The obtained silver nanoparticles were purified by centrifuging in a Remi cooling centrifuge at $10,000 \mathrm{rpm}$ for $30 \mathrm{~min}$. The pellets obtained were dispersed in deionized three times to remove water solubles.

\section{Characterization of synthesized silver nanoparticles}

\section{UV-Vis spectral analysis}

Biological mediated reductions of silver salts were monitored by UVVis spectroscopy. Absorption spectra were obtained using Shimadzu company model-UV3600 UV-Vis spectrophotometer using quartz cuvette and distilled water as a reference. Spectral readings of UVVis were recorded between 350 and $550 \mathrm{~nm}$ for synthesized silver nanoparticles.

\section{Scanning electron microscopy (SEM) and EDAX}

Size, shape and morphology of silver nanoparticles were resolved by scanning electron microscopy by using ZEISS Ultra 55 SEM machine operated $5 \mathrm{kVat}$ Center for Nanoscience and Engineering, Indian Institute of Science, Bengaluru. A thin film of the sample was prepared on a carbon coated copper grid by just keeping the very small amount of the sample on the grid. The readings and photographic scan were taken at 50.00, 75.00 and 100.00 magnification with constant voltage and at different angles.

\section{X-ray diffraction measurements (XRD)}

Crystalline metallic properties of AgNPs were examined by XRD (Rigaku, SmartLab X-ray Diffractometer) at Center for Nanoscience and Engineering, Indian Institute of Science, Bangaluru at a voltage of $40 \mathrm{keV}$ and a current of $30 \mathrm{~mA}$ with $\mathrm{Cu}$ Ko radiation, step size0.02 , speed $-5^{\circ} / \mathrm{min}$ with a wavelength of $1.5418 \AA$ and at $2 \theta$ angle.

\section{Antimicrobial activity of silver nanoparticles}

Microbial cultures: Escherichia coli, Pseudomonas aeruginosa, Enterobacter and Klebsiella pneumonia were collected from Department of Microbiology of Shridevi Institute of Medical Sciences and Research Hospital, Tumakuru, Karnataka of India and were maintained in nutrient broth.

The antimicrobial assay was carried out by Agar well diffusion method. Overnight samples were swabbed on the plates containing Muller Hinton Agar (MHA) medium (Hi-Media). Wells were prepared in the medium using sterile gel puncture. $50 \mu \mathrm{g} / \mathrm{ml}$ and $100 \mu \mathrm{g} / \mathrm{ml}$ of synthesized silver nanoparticle solution was added to wells. Sterile distilled water and antibiotic amphicillin were added as negative and positive control respectively. Petri plates were kept for incubation for $24 \mathrm{~h}$ at $37^{\circ} \mathrm{C}$.

\section{Statistical analysis}

All the experiments were performed in triplicate, and the data were expressed as mean.

\section{RESULTS AND DISCUSSION}

The extracellular green synthesis of silver nanoparticles occurred during the exposure of the leaf extract to $1 \mathrm{mmol}$ aqueous silver nitrate solution. The complete reduction of silver ions was observed 2 -3h. The color change of the reaction was observed during the incubation period because the formation of silver nanoparticles is able to produce a specific color of the reaction mixtures because of their unique properties. The appearance of bluish color is a conclusive indication of the formation of silver nanoparticles in the reaction mixture (fig. 2). Due to the presence of coherent excitation of all the 'free' electrons within the conduction band, the color could be exhibited by the metal particles and leading to an in-phase oscillation which is known as surface plasmon resonance (SPR) [20].
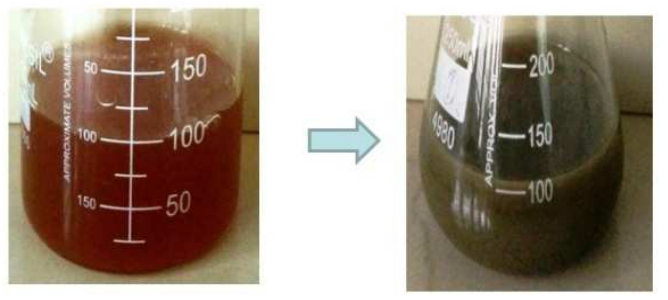

Fig. 2: Simaroubaglauca leaf extract, before and after treating with silver nitrate

UV-vis spectroscopy technique was applied to monitor the SPR absorbance band of silver nanoparticles synthesized using leaf extract of Simaroubaglauca and it was centered at $440 \mathrm{~nm}$ and relentlessly increments in intensity as a function of the time of reaction without any shift in the peak wavelength (fig. 3) [21]. The frequency and width of the surface plasmon absorption relies on the size and shape of the metal nanoparticles and in addition on the dielectric constant of the metal itself and the encompassing medium.

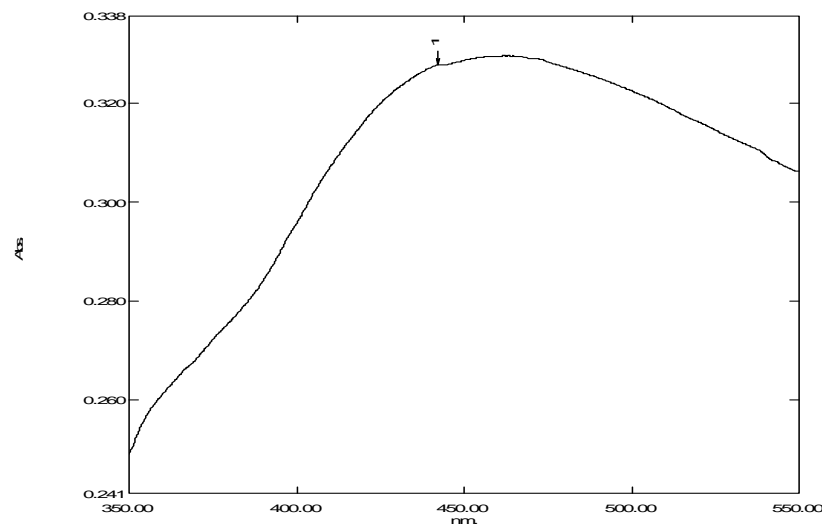

Fig. 3: UV-vis spectrum of silver nanoparticles synthesized using leaf extract Simaroubaglauca
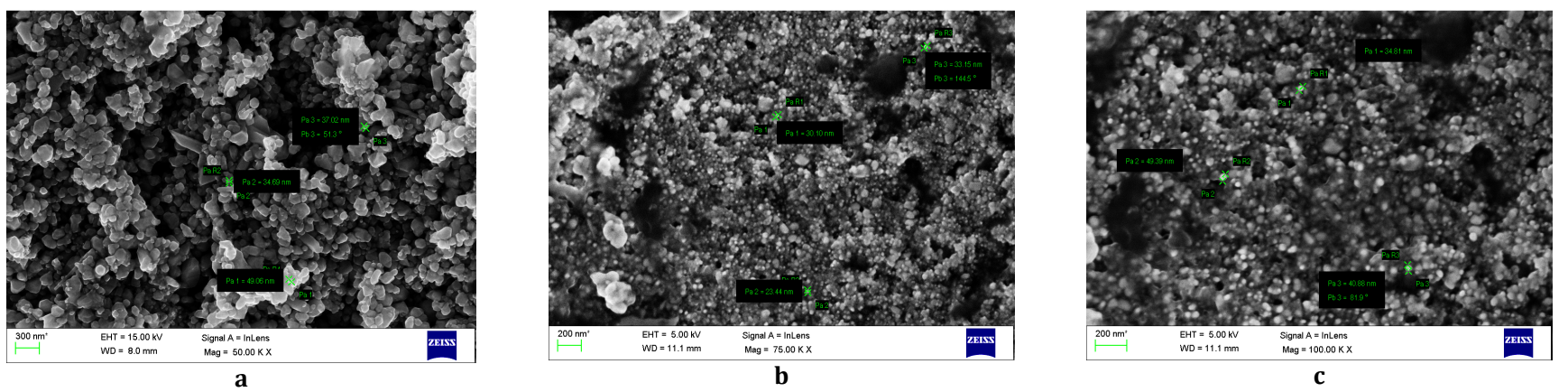

Fig. 4: SEM photographs of silver nanoparticles obtained using leaf extract Simaroubaglauca, a. 50.00, b. 75.00, c. 100.00 
The microstructural qualities of the synthesized silver nanoparticles were studied by SEM (fig. 4). Little round shaped outgrowths of silver nanoparticles agglomerates with homogenous dissemination. The silver nanoparticles were generally circular, and the size was evaluated to be in the range in the vicinity of 23 and $49 \mathrm{~nm}$. The EDX investigation of silver nanoparticles affirms that the nanoparticles are in fact silver nanoparticles (fig. 5). It demonstrates that silver nanoparticles were upheld on the natural grid from the Simaroubaglauca. The peak of Ag component is most likely from the silver nitrate.

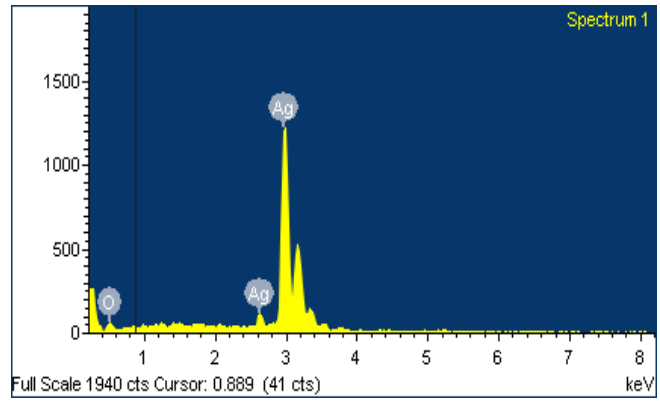

Fig. 5: EDAX spectrum of silver nanoparticles

\section{Powder X-ray diffraction studies of silver nanoparticles}

X-ray diffraction studies have provided an excellent result that confirms the biosynthesis of silver nanoparticles (AgNPs) from leaf extract of Simaroubaglauca. The bioreductive process has generated the cubic crystalline structure of silver nanoparticles. The XRD pattern shows distinct peaks of diffraction at $2 \theta$. A number of Bragg reflections with $2 \theta$ values of $27.60^{\circ}, 32.10^{\circ}, 38.00^{\circ}, 44.17^{\circ}, 46.08^{\circ}$ (222), $64.42^{\circ}(400), 77.32^{\circ}(420)$ and $81.40^{\circ}$, corresponded to the (111), (200), (220), (311), (222), (400), (420) and (422) face centered cubic structures of silver and compared with the data of JCPDS (Joint Committee on Powder Diffraction Standards), File No. 85-1355. The average particle sizes were calculated according to Debye-Scherrer equation [22]. According to the equation, average silver nanoparticle sizes of Simaroubaglauca were found to be 2.310-19.929 $\mathrm{nm}$ range at different $\theta$ values (fig. 6). Earlier, the similar results have been reported for silver nanoparticles [23].

\section{Antibacterial activities of Au and Ag nanoparticles}

In our investigation, the synthesized silver nanoparticles have been evaluated for their antibacterial activities against human pathogens such as Gram-negative Escherichia coli, Pseudomonasaeruginosa, Enterobacter and Klebsiella pneumonia at (50 $\mu \mathrm{g} / \mathrm{ml}$ and $100 \mu \mathrm{g} / \mathrm{ml}$ ) different concentration. Silver nanoparticles shown zones of inhibition $30 \mathrm{~mm}$ and $32 \mathrm{~mm}, 5 \mathrm{~mm}$ and $8 \mathrm{~mm}, 4 \mathrm{~mm}$ and $6 \mathrm{~mm}$ and $3 \mathrm{~mm}$ and $5 \mathrm{~mm}$ against Escherichia coli, Pseudomonasaeruginosa, Enterobacter and Klebsiella pneumonia respectively at the concentration of $50 \mu \mathrm{g} / \mathrm{ml}$ and $100 \mu \mathrm{g} / \mathrm{ml}$ (fig. 7). Both the concentration of silver nanoparticles have indicated practically comparative outcomes have appeared by standard amphicillin against Escherichia coli whereas other pathogens against which have failed to show significant results. Silver nanoparticles have shown their effect against Escherichia colia Gram-negative bacteria and it was suggested that the effect would be size and dose dependent [24].

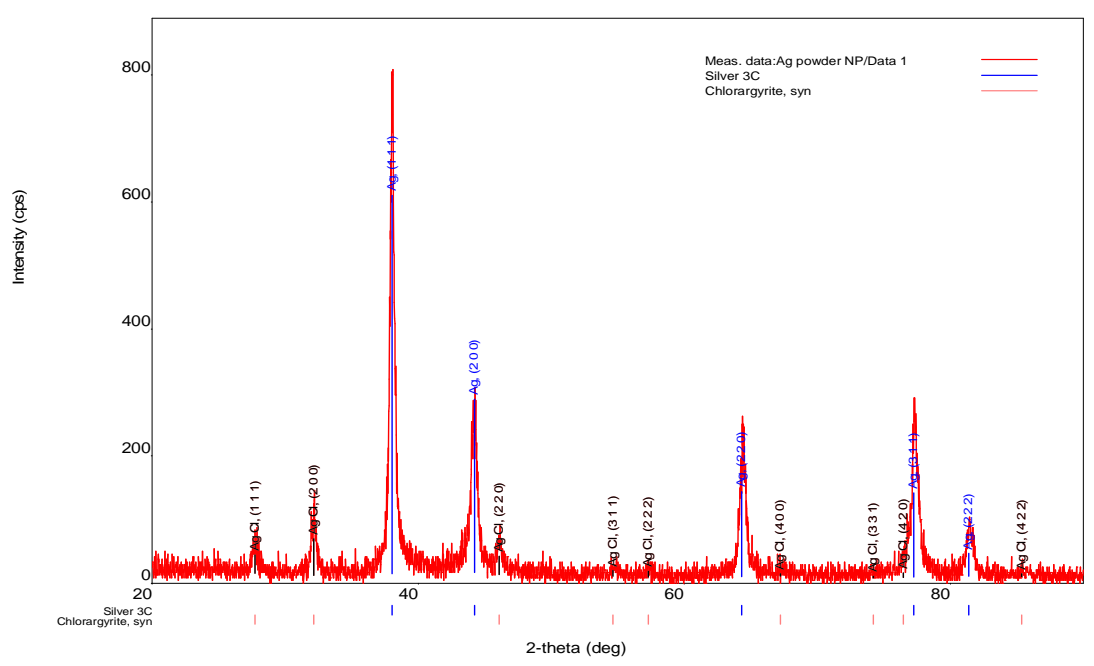

Fig. 6: X-ray diffraction crystallographic studies of silver nanoparticles from leaf extract of Simaroubaglauca

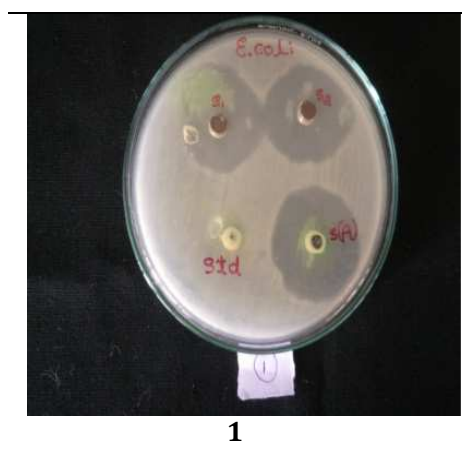

1. Escherichia coli

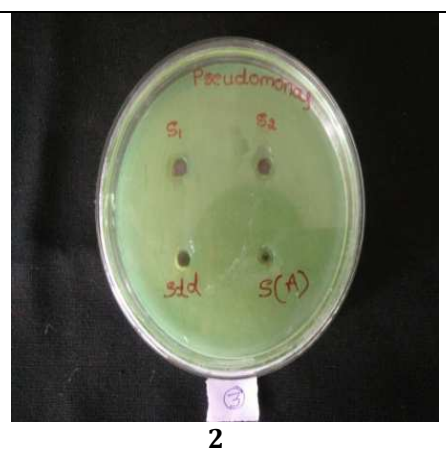

2. Pseudomonas aeruginosa

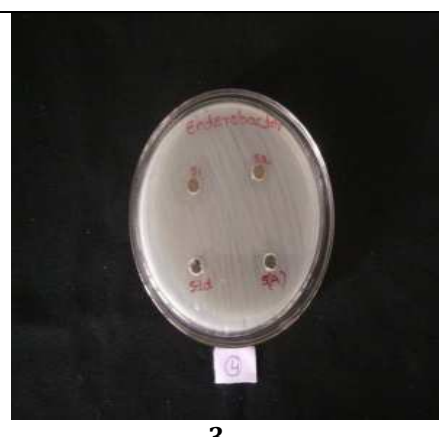

3. Enterobacter

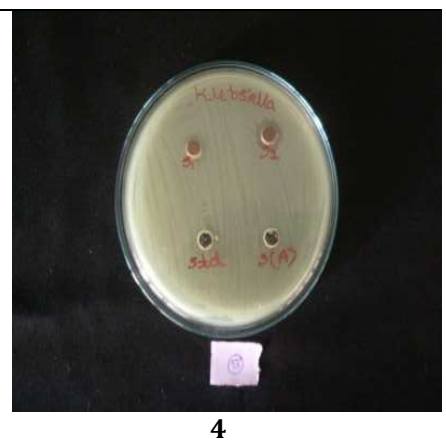

4. Klebsiella pneumonia

Fig. 7: Antibacterial activity of synthesized silver nanoparticles, $S 1-50 \mu \mathrm{g} / \mathrm{ml}$. S2-100 $\mu \mathrm{g} / \mathrm{ml}$. Std-Distilled water. S(A)-Amphicillin 


\section{CONCLUSION}

The medicinally significant aqueous leaf extract of Simaroubaglauca was found to behave as a reducing agent for the production of silver nanoparticles. The synthesized silver nanoparticles have been characterized by UV-vis, SEM-EDAX and XRD to determine the sizes and shapes of the silver nanoparticles. The developed method is one of the excellent methods to produce silver nanoparticles in absence of toxic reducing chemicals. Our outcomes suggest that the biologically synthesized silver nanoparticles are most prominent against human pathogens.

\section{CONFLICT OF INTERESTS}

Declare none

\section{REFERENCES}

1. Benjamin LO, Francesco S. Antibacterial activity of silver nanoparticles: a surface science insight. Nano Today 2015;10:339-54.

2. Swarnali M, Deepak K, Gadadhar B, Sudip KG, Jayasree KL. Antimicrobial activities of silver nanoparticles synthesized from Lycopersiconesculentum extract. J Anal Sci Technol 2014;5:40:1-7.

3. Parikh DV, Fink T, Rajasekharan K, Sachinvala ND, Sawhney APS, Calamari TA, et al. Antimicrobial silver/sodium carboxymethyl cotton dressings for burn wounds. Text Res J 2005;75:134-8.

4. Ulkur E, Oncul O, Karagoz H, Yeniz E, Celikoz B. Comparison of silver-coated dressing (ActicoatTM), chlorhexidine acetate $0.5 \%$ (Bactigrass $\AA$ ), and fusidic acid $2 \%$ (Fucidin $®$ ) for topical antibacterial effect in methicillin-resistant staphylococcicontaminated, full-skin-thickness rat burn wounds. Burns 2005;31:874-7.

5. Jeong SH, Yeo SY, Yi SC. The effect of filler particle size on the antibacterial properties of compounded polymer/silver fibres. J Mater Sci 2005;40:5407-11.

6. Lee HY, Park HK, Lee YM, Kim K, Park SB. A practical procedure for producing silver nanocoated fabric and its antibacterial evaluation for biomedical applications. Chem Commun 2007;28:2959-61.

7. Yuranova T, Rincon AG, Bozzi A, Parra S, Pulgarin C, Albers P, et al. Antibacterial textiles prepared by RF-plasma and vacuumUV mediated deposition of silver. Photochem Photobiol 2003;161:27-34.

8. Samuel U, Guggenbichler JP. Prevention of catheter-related infections: the potential of a new nanosilver-impregnated catheter. Int J Antimicrob Agents 2004;23:75-8.

9. Alt V, Bechert T, Streinrucke P, Wagener M, Seidel P, Dingeldein $\mathrm{E}$, et al. Domanne $\mathrm{E}$, schnettler $\mathrm{r}$ an in vitro assessment of the antibacterial properties and cytotoxicity of nanoparticulate silver bone cement. Biomaterials 2004;25:4383-91.

10. Rupp ME, Fitzgerald T, Marion N, Helget V, Puumala S, Anderson JR, et al. Effect of silver-coated urinary catheters: efficacy, cost-effectiveness antimicrobial resistance. Am J Infect Control 2004;32:445-50.
11. Chenousova S, Epple M. Silver as an antibacterial agent: ion, nanoparticle, and metal. Angew ChemInt Ed Engl 2013; 4:1636-53.

12. Kalsen HJ. Historical review of the use of silver in the treatment of burns. I. Early uses. Burns 2000;26:2:117-30.

13. Fuhrmann GF, Rothstein A. The mechanism of the partial inhibition of fermentation in yeast by nickel ions. Biochim Biophys Acta 1968;163:331-8.

14. Miller LP, Mc Callan SEA. The toxic action of metal ions to fungus spores. J Agric Food Chem 1957;5:116-22.

15. Rayman MK, LoT C, Sanwal BD. Transport of succinate in Escherichia coli. II. Characteristics of uptake and energy coupling with transport in membrane preparations. J Biol Chem 1972;247:6332-9.

16. Schreurs WJ, Rosenberg H. Effect of silver ions on transport and retention of phosphate by Escherichia coli. J Bacteriol 1982;152:7-13.

17. Joseph JD, Jeffrey TB, Jude CO, Peter MD, Oliver NM, Ibrahim M. Antimicrobial efficacy of biosynthesized silver nanoparticles from different solvent extracts of Waltheriaamericana root. J Anal Sci Technol 2016;7:23.

18. Santhana LK, Sangeetha D, Sivamani S, Tamilarasan M, Rajesh $\mathrm{TP}$, Anandraj B. In vitro antibacterial, antioxidant, haemolytic, thrombolytic activities and phytochemical analysis of Simaroubaglauca leaves extracts. Int J Pharm Sci Res 2014;5:432-7.

19. Nagaraj B, AgnieszkaSobczak-Kupiec, Rebecca IF, Salman D. Bioreduction of chloroaurate ions using fruit extract Punicagranatum (Pomegranate) for synthesis of highly stable gold nanoparticles and assessment of its antibacterial activity. Micro Nano Lett 2013;8:400-4.

20. Nithya R, Ragunathan R. Synthesis of the silver nanoparticle using pleurotus Sajorcaju and its antimicrobial study. Digest J Nanomaterials Biostructures 2009;4:623-9.

21. Chandrappa CP, Govindappa M, Chandrasekar N, Sonia S, Sepuri 0, Channabasava R. Endophytic synthesis of silver chloride nanoparticles from Penicillium sp. of Calophyllumapetalum. Adv Nat Sci: Nanosci Nanotechnol 2016;7:1-5.

22. Nagaraj B, Akber I, Yong RL. Preparation of $\mathrm{Au}$ and $\mathrm{Ag}$ nanoparticles using Artemisia annua and their in vitro antibacterial and tyrosinase inhibitory activities. Mater Sci Eng Carbon 2014;43:58-64.

23. Baker RA, Tatum JH. Novel anthraquinones from stationary cultures of Fusariumoxysporum. J Ferment Bioeng 1998; 85:359-61.

24. Mritunjai S, Shinjini S, Prasad S, Gambhir IS. Nanotechnology in medicine and antibacterial effect of silver nanoparticles. Digest J Nanomater Biostructures 2007;3:115-22.

\section{How to cite this article}

- $\quad$ CP Chandrappa, N Chandrasekar, M Govindappa, Chaitra Shanbhag, Uttam Kumar Singh, Jayashri Masarghal. Antibacterial activity of synthesized silver nanoparticles by Simaroubaglauca against pathogenic bacteria. Int J Curr Pharm Res 2017;9(4):19-22. 